\title{
Satellite Observation on the Exceptional Intrusion of Cold Water in the Taiwan Strait
}

\author{
Yi Chang ${ }^{1}$, Kuo-Tien Lee ${ }^{1,2}$, Ming-An Lee ${ }^{1,3, *}$, and Kuo-Wei Lan ${ }^{1}$ \\ ${ }^{1}$ Department of Environmental Biology and Fisheries Science, National Taiwan Ocean University, Keelung 20224, Taiwan, ROC \\ ${ }^{2}$ Center for Marine Bioscience and Biotechnology, National Taiwan Ocean University, Keelung 20224, Taiwan, ROC \\ ${ }^{3}$ Remote Sensing Laboratory of Taiwan Ocean Research Institute, Keelung 20224, Taiwan, ROC
}

Received 18 April 2008, accepted 7 August 2008

\begin{abstract}
We used satellite-derived sea surface temperature (SST) data for the winters of 1996 - 2008 to examine the exceptional intrusion of China Coastal Current into the Taiwan Strait. The long term observation reveals that, in 1999 and 2000, the strong wind $\left(>6 \mathrm{~m} \mathrm{~s}^{-1}\right)$ lasted for 12 and 16 days with a drop of 5.35 and $5.5^{\circ} \mathrm{C}$ in SST, respectively. The satellite data also showed that the China Coastal Current intruded from the north of the Chang-Yuen Ridge into the waters surrounding the Peng-Hu Islands, with wind speeds of more than $6.7 \mathrm{~m} \mathrm{~s}^{-1}$ lasted for 30 days during the same period. The exceptional intrusion resulted in the minimum SST of $12.6^{\circ} \mathrm{C}$ on 16 February $2008,7.8^{\circ} \mathrm{C}$ lower than the 12 -year average of February $\left(20.4^{\circ} \mathrm{C}\right)$. The higher SST $\left(>18^{\circ} \mathrm{C}\right)$ appeared after 21 February 2008 indicating the northward withdrawal of the cold water. During the period of $15-21$ February 2008, the China Coastal Current intruded to as far south as the water around Peng-Hu Islands.

To compare the El Niño/La Niña events with regard to SST and wind speed, we found that SST was warmer in the El Niño winters $(1998,2003$ - 2005) than in the La Niña winters (1999 - 2001, 2008), and wind speed was more intensive in the La Niña winters $(1996,1999$ - 2001, 2006, 2008) than in the El Niño winters $(1998,2003$ - 2005, 2007). In the winter of 2008, the wind speed sharply increased on 26 January and lasted for more than 30 days, with wind speed peaked at $7.36 \mathrm{~m} \mathrm{~s}^{-1}$. The monthly SST in February 2008 was about $7^{\circ} \mathrm{C}$ lower than that of the 12-year average. This decadal oscillation shows that the wind variation corresponds well with the El Niño/La Niña events, especially, the continuous strong wind in the La Niña winter of 2008. We thus suggest the influence of climate change on wind speed to be responsible for the change in the current. The exceptional cold SSTs around Chang-Yuen Ridge and Peng-Hu Islands in February of 2008 probably were, therefore, caused by the more southward intrusion of China Coastal Current driven by the continuous strong wind.
\end{abstract}

Key words: Sea surface temperature, China Coastal Current, Taiwan Strait

Citation: Chang, Y., K. T. Lee, M. A. Lee, and K. W. Lan, 2009: Satellite observation on the exceptional intrusion of cold water in the Taiwan Strait. Terr. Atmos. Ocean. Sci., 20, 661-669, doi: 10.3319/TAO.2008.08.07.01(Oc)

\section{INTRODUCTION}

The Taiwan Strait is a shallow channel connecting the East China Sea in the north and the South China Sea in the south. The cold current from north and the warm current from south flow through the Strait consisting of complex topographic features. The major shallow topographies are the Chang-Yuen Ridge off the western coast of Taiwan and the Taiwan Bank in the southwest part of the Strait (Fig. 1). The variation of depth contributes to the formation of thermal fronts between the cold and warm water masses. The

\footnotetext{
* Corresponding author

E-mail:malee@ntou.edu.tw
}

warm current flows northward into the Strait all year round, while the northeasterly monsoon in winter lessens the strength of the warm current and drives the cold current from the north into northwest side of the Strait (Jan et al. 2002).

In winter, the flow patterns shown in Fig. 1 reveal that the main of China Coastal Current on the western side of the Strait was moving southward along the Chinese coasts. A portion of the China Coastal Current was blocked around the Chang-Yuen Ridge and turned back northward at the expense of southward intrusion (grey arrows in Fig. 1). Meanwhile the Kuroshio Branch Current from the Peng-Hu Chan- 
nel was blocked at the Chang-Yuen Ridge (black arrows in Fig. 1). Previous studies (Lee et al. 2003; Kuo and Ho 2004) examined the SST (sea surface temperature) patterns in the Taiwan Strait. They showed that in wintertime the dominant spatial variance in sea surface temperature (SST) is consistent with a quasi-permanent front at the Chang-Yuen Ridge. Jan et al. (2002) also indicated that the warm tongue of Kuroshio Branch Current could occasionally advance more northward from the Peng-Hu Channel. Again, most of the previous studies suggest that the cold China Costal Current is blocked north of the Chang-Yuen Ridge in winter.

However, the climatological composite data and the in situ hydrographic data can not provide a comprehensive vision of short-term variation in SST fields and SST fronts. The attempt of this study is to observe the sharp change of SST in the Taiwan Strait during the northeasterly monsoon season of January and February 2008. We focus on the description of high-resolution features of SST in both daily and long-term composite views, and we also discuss the short SST change related to variation of monsoon in the Strait.

\section{DATA AND METHOD}

Wintertime (January and February) satellite data derived form AVHRR (Advanced Very High Resolution Radiometer) sensors in a 13-year period (1996 - 2008) was archived from the regional HRPT (High Resolution Picture Transmission) data library at the National Taiwan Ocean University (Lee et al. 2003). SST images with high-resolution $(1.1 \mathrm{~km})$ were produced by the MCSST (Multi Channel Sea Surface Temperature) algorithm (McClain et al. 1985). The bias and root mean square (RMS) between AVHRR and in situ data were 0.01 and $0.64^{\circ} \mathrm{C}$ respectively in waters around Taiwan Waters (Lee et al. 2005b). SST images derived from AMSR-E (Advanced Microwave Scanning Radiometer-Earth Observing System) with $25-\mathrm{km}$ spatial resolution were also used in order to cover the gap of AVHRR data in the cloudy days of study period. We collected the Version-4 ocean products of AMSR-E data during the same period from the web site of Remote Sensing Systems http:// www.ssmi.com (Hosoda and Kawamura 2004). We then compared the AMSR-E SST with AVHRR SST images. A $3 \times 3$ array of AVHRR SST around the cloud-free pixel of AMSR-E was averaged during February of 2008. 509 matched-up pixels were selected wherein a comparison (Fig. 2) indicated that the AMSR-E SST was linearly correlated with AVHRR SST with the bias and RMS of 0.11 and $0.82^{\circ} \mathrm{C}$ respectively. Thus, the AMSR-E SST corresponded well with the AVHRR SST and could allow us to monitor the SST in the study area for covering the gap of AVHRR under cloudy conditions.

In order to observe the annual and inter-seasonal variations of wintertime SST in the Taiwan Strait, the time series of daily SST has been estimated in this study. We calculated the mean SST of cloud-free pixels in the 0.5 degree square northwest of the Peng-Hu Islands, central Taiwan Strait (open square in Fig. 1: $23.5-24.0^{\circ} \mathrm{N}, 119.0-119.5^{\circ} \mathrm{E}$ ). According to Jan and Chao (2003), the current flow of Kuroshio Branch Current from the Peng-Hu Channel in winter seems to be correlated with the changing winds around the Peng-Hu Islands. We thus collected the daily wind speed

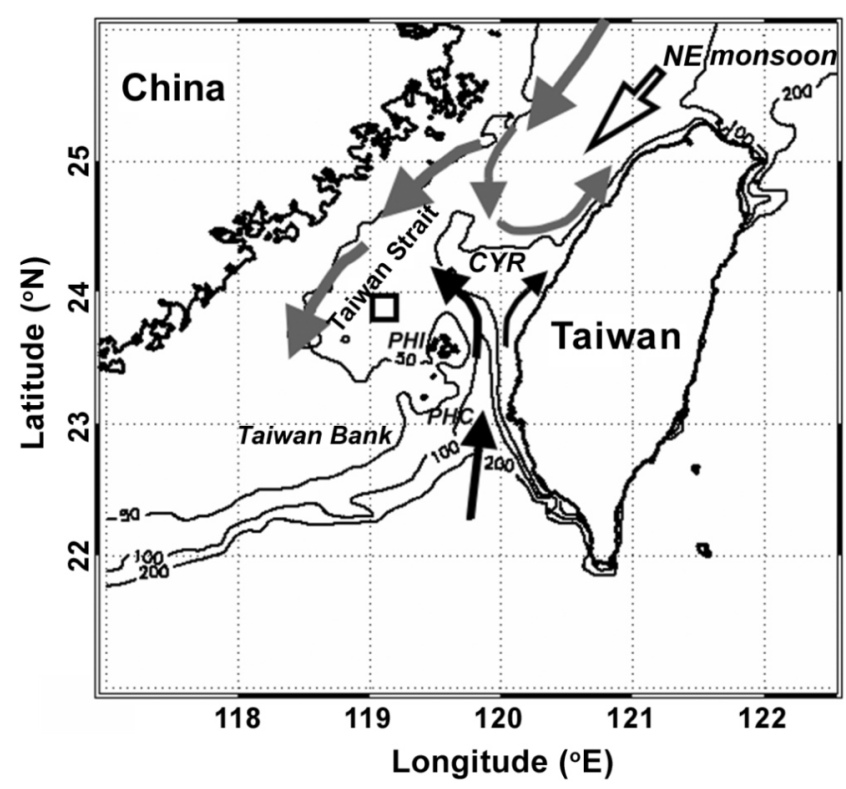

Fig. 1. Map of bottom topography and flow patterns in winter. The black contours indicate coast lines and bottom depth in meters. CYR, PHI, and PHC represent the location of the Chang-Yuen Ridge, Peng$\mathrm{Hu}$ Islands and Peng-Hu Channel, respectively. Grey and black arrows indicate the China Coastal Current and Kuroshio Branch Current (redraw from Jan et al. 2002).

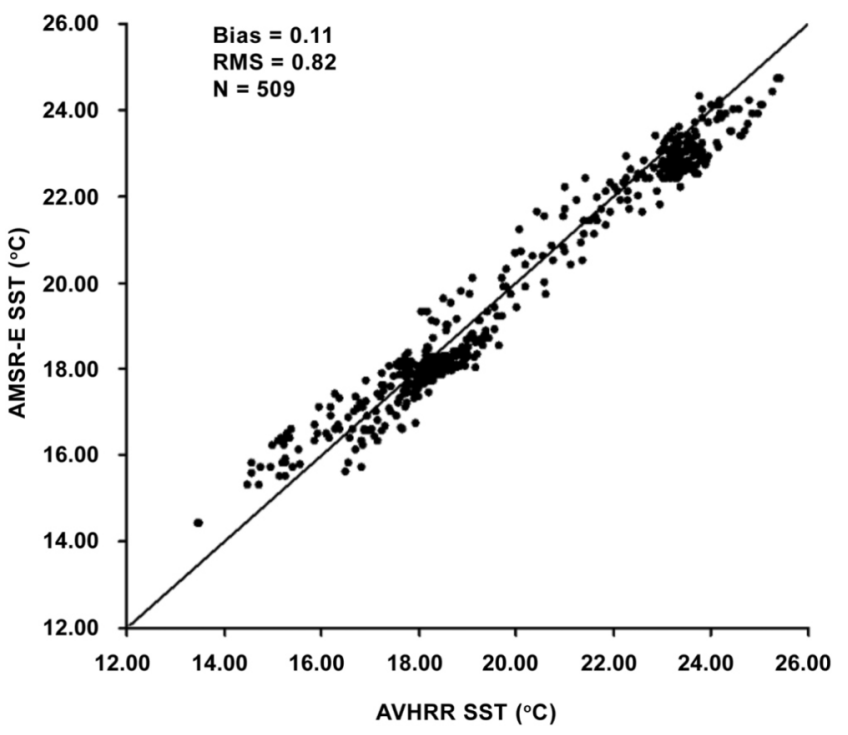

Fig. 2. The relationship between satellite-derived SST of AMSR-E and AVHRR in the study area. 
data and monthly rainfall data from one gauge station on the Peng-Hu Islands. A seven day moving average of wind speed was used to investigate the variation compared with the SST change. In order to compare the SST variation with climate change in the study area, the Oceanic Niño Index (ONI) (http://www.cpc.noaa.gov/products) was collected. The ONI was estimated by the 3-month running mean of SST anomalies in the Niño 3.4 region $\left(5^{\circ} \mathrm{N}-5^{\circ} \mathrm{S}, 120^{\circ}-170^{\circ} \mathrm{W}\right)$, based on the 1971 - 2000 base period. For historical purposes cold and warm episodes (negative and positive numbers) are defined when the threshold was met with a minimum of 5 consecutive over-lapping seasons (Xue et al. 2003).

\section{SST COMPOSITE MAPS IN WINTER}

The twelve year (1996 - 2007) monthly mean composite SST maps in winter are shown in Figs. 3a and b. In January (Fig. 3a), the cold China Coastal Current $\left(<18^{\circ} \mathrm{C}\right)$ flowed southward along the Chinese coast, while the warm Kuroshio Water and South China Sea Water $\left(>20^{\circ} \mathrm{C}\right)$ were surrounded the Peng-Hu Islands in the eastern Taiwan Strait. A cold water tongue $\left(<17^{\circ} \mathrm{C}\right)$ intruded into the central Taiwan Strait from the Chinese coast (arrow). This cold water tongue was then blocked at the northern edge of the Chang-Yuen Ridge. Alternately, the warm water $\left(>20^{\circ} \mathrm{C}\right)$ from the Peng-Hu Channel was also blocked south of the Ridge. By February (Fig. 3b), the water of lower than $15^{\circ} \mathrm{C}$ was still occupying waters along the Chinese coast, however, the cold water tongue north of CYR faded gradually. In the meantime the warm water of higher than $22^{\circ} \mathrm{C}$ flowed northward into the northern Taiwan Strait, extending more northward along the southwest edge of the Chang-Yuen Ridge (arrow in Fig. 3b).

The monthly maps depicting the winter of 2008 were contrary to the typical features of long-term composites. The SST in January (Fig. 3c) indicated that the cold water tongue was not distinct in the northern Taiwan Strait, in contrast, the warm water guided by the Peng-Hu Channel extended more northward and intruded into the northern end of Chang-Yuen Ridge. Yet, clearly a cold water mass of lower than $10^{\circ} \mathrm{C}$ (blue color) flowed into the western Taiwan Strait along the Chinese Coast in February of 2008 (Fig. 3d). Moreover, the cold China Coastal Current was moving more southward and reached the Taiwan Bank. Unlike the features of the long-term average, the cold water tongue intruded into the

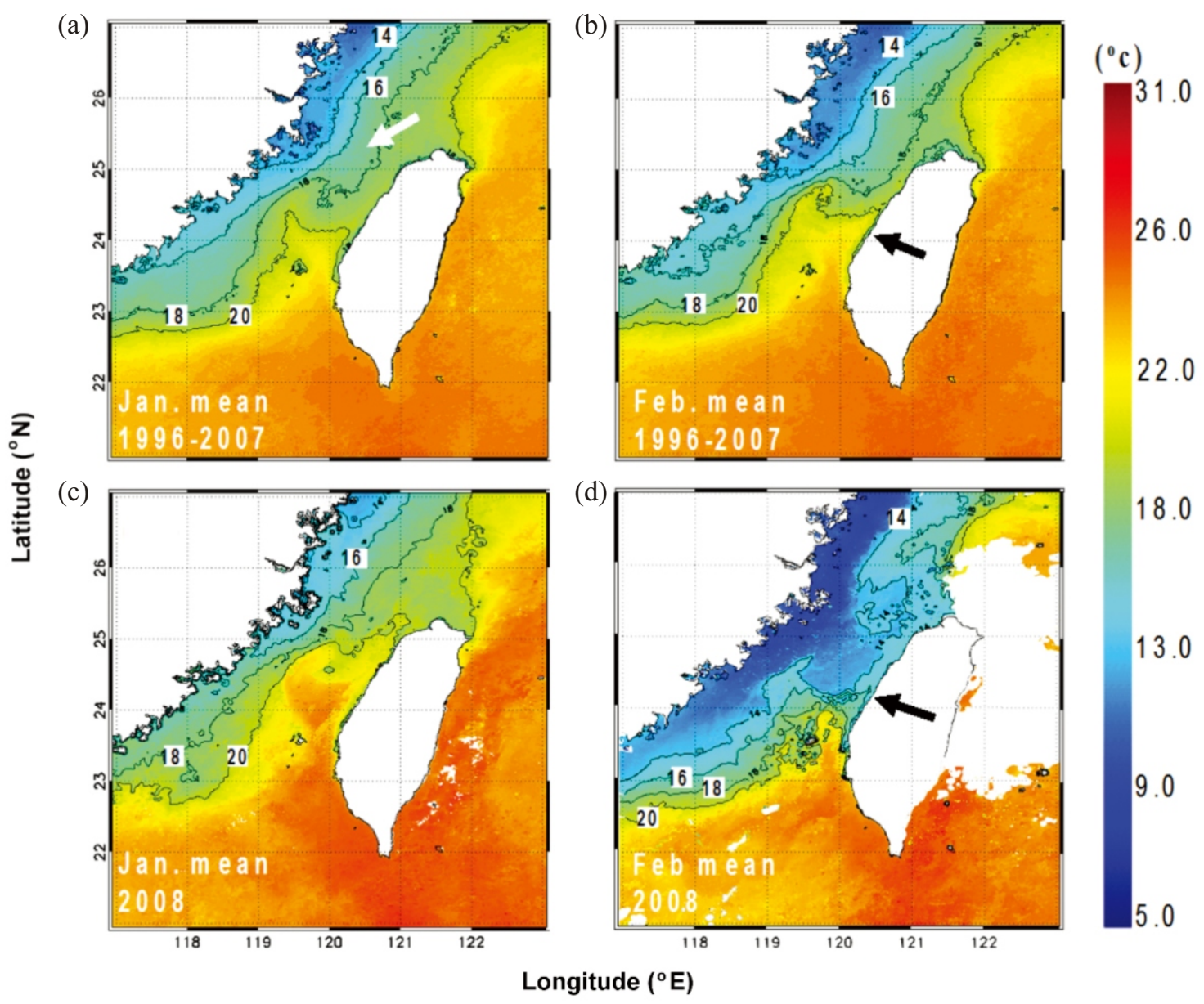

Fig. 3. 12-year monthly mean SST maps in January (a) and February (b), and the monthly mean maps of 2008 in January (c) and February (d). 
south of Chang Yuen Ridge (arrow in Fig. 3d) with the SST lower than $13^{\circ} \mathrm{C}$ in February of 2008. Meanwhile, the northward intrusion of warm water in the southeastern Taiwan Strait was blocked near the north end of the Peng-Hu Channel. As a consequence, the most of the water around the Peng-Hu Islands was lower than $15^{\circ} \mathrm{C}$ instead of the warmer water in the January of 2008.

Compared with the monthly SST of the 12-year average, Fig. 4 illustrates the spatial variance in SST of the Taiwan Strait in the winter of 2008. SST differences map for January (Fig. 4a) revealed that the SST in 2008 was about $1{ }^{\circ} \mathrm{C}$ higher than that of the 12-year average in most waters. However, a maximum SST difference $\left(>5^{\circ} \mathrm{C}\right)$ in crescent shape was found on the Chang-Yuen Ridge. In contrast, SST difference map in February of 2008 (Fig. 4b) showed a significant cooling feature in the Strait. The SST along the Chinese coasts thus witnessed a decrease of about $3.5^{\circ} \mathrm{C}$ and SST in the north of Taiwan Strait with a decrease of more than $7^{\circ} \mathrm{C}$ than average (arrow) and distinguished cold feature extending into the water around the Peng-Hu Islands.

\section{DISCUSSION}

Satellite-derived SST fields are rich in structure reflecting important oceanic environmental dynamics related to currents, fronts, and climate change. Because of the constantly increasing amount of highly accurate remote sensing data available for the waters around Taiwan (Lee et al. $2005 \mathrm{~b}$ ), there has been a rising ability to monitor the SST variation in different time scales from hours to years. Therefore, the present SST images, as well as previous studies, in the Taiwan Strait show that the winter variability in SST was dominated by a seasonal current cycle of cold and warm waters. Typical features of SST in winter are dominated by the cold water on the northwest side and blockage of warm water on the southeast side of the Strait (Figs. 3a, b). This blocked warm water was confirmed to be the Kuroshio Branch Current (Jan et al. 2006). As a consequence, a quasipermanent SST front was formed around the Chang-Yuen Ridge, and the $20^{\circ} \mathrm{C}$ isotherm was suggested to be the boundary between the cold China Coastal Current and warm Kuroshio Branch Current in winter ( Jan et al. 2002; Lee et al. 2005a). During winter, the southward penetration of the China Coastal Current peaked in January while a cold tongue was observed north of Chang-Yuen Ridge (arrow in Fig. 3a). The cold tongue was suggested to be a portion of the China Coastal Water deflected by the Chang-Yuen Ridge and turns northeastward (Jan et al. 2002). Recent studies of highresolution SST front features of the winter waters (Chang et al. 2006; Li et al. 2006) further indicated that the major SST fronts in the Strait distributed along the 50-m isobath near the west side of the Chang-Yuen Ridge. It is, therefore, well understood that the north part of Chang-Yuen Ridge should be an important geographic zone to separate the cold water in the northwest and the warm water in the southeast.

Our results also reveal inter-seasonal variation in the interaction between cold and warm water. The cold water tongue reached the southern edge of the Chang-Yuen Ridge in January; then the Kuroshio Branch Current increased in strength gradually and intruded into the northern Taiwan Strait in February. However, the monthly SST images in 2008 were contrary to the long-term average features and

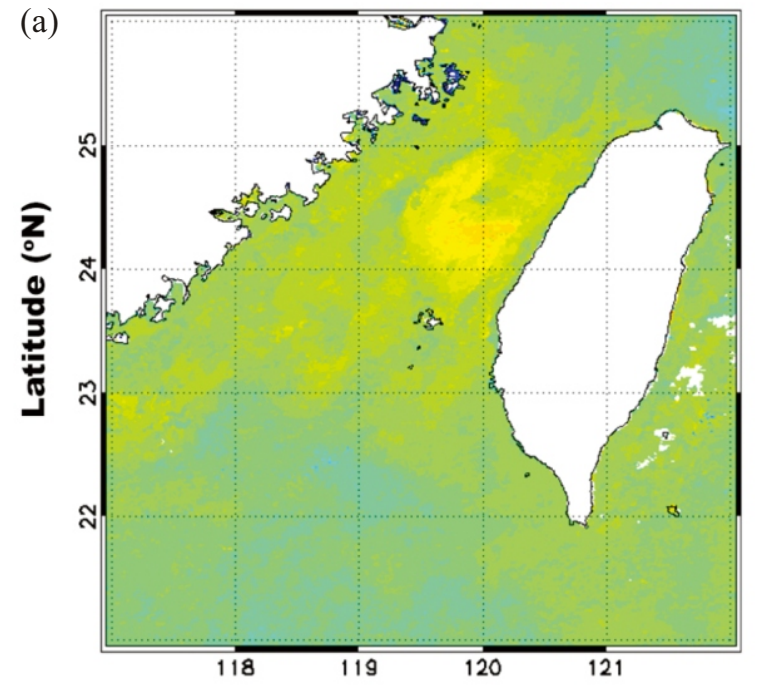

(b)

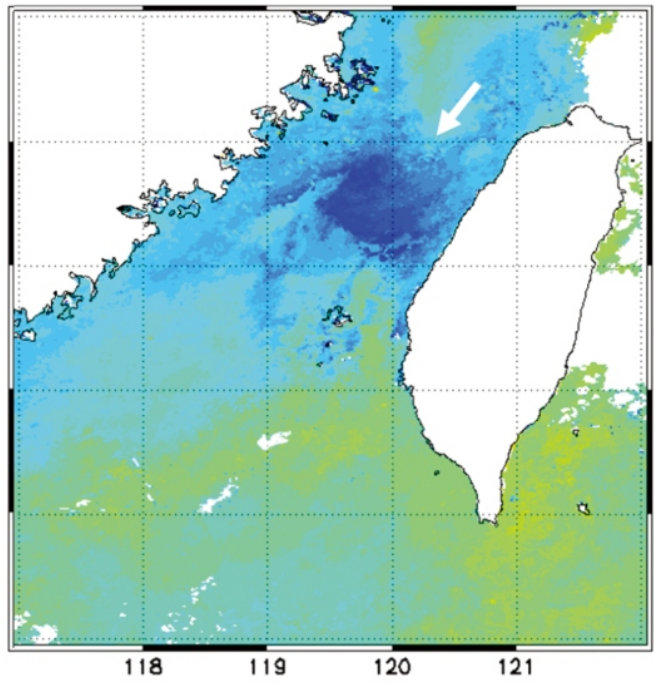

Longitude ( $\left.{ }^{\circ} \mathrm{E}\right)$

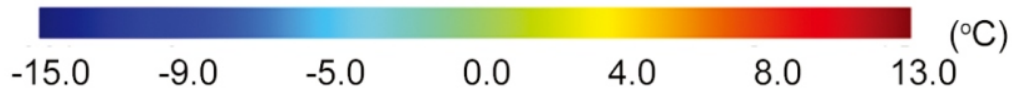

Fig. 4. SST difference maps in January (a) and February (b). The SST difference was monthly mean of 2008 minus the 12 -year monthly mean. 
reveals clearly that the Kuroshio Branch Current reached the Chang-Yuen Ridge in January (Figs. 3c, 4a), and the China Coastal Current intruded to as far south as the northern end of the Peng-Hu Channel and blocked the Kuroshio Branch Current in February (Figs. 3d, 4b).

Based on the result posted by Lee et al. (2005a), we regarded the $20^{\circ} \mathrm{C}$ isotherm as an indicator to examine the variation in the intrusion of the China Coastal Current before and after the exceptional cold SST event in 2008 . The $20^{\circ} \mathrm{C}$ isotherm west of $119^{\circ} \mathrm{E}$ varied slightly on the Taiwan Bank, while the $20^{\circ} \mathrm{C}$ isotherm east of $119^{\circ} \mathrm{E}$ varied sharply from the north of the Chang-Yuen Ridge to the Peng-Hu Channel (Fig. 5). The $20^{\circ} \mathrm{C}$ isotherm of the 12 -year average (thin black contour) was restricted to the central Taiwan Strait. The northern part of this boundary coincides with the northern edge of the Chang-Yuen Ridge, which separates the cold water from the warm Kuroshio Branch Current in the northern Taiwan Strait. However, these isotherms on 15 and 21 February (broad contours in black and gray in Fig. 5) were near the Peng-Hu Channel and then receded gradually northward to the south of the Chang-Yuen Ridge after 28 February (thin gray contour). Otherwise, from the shifting and the reverse C-shaped $20^{\circ} \mathrm{C}$ isotherms (arrows in Fig. 5), it is suggested that the China Coastal Current intruded not only from the north of the Chang-Yuen Ridge, but also from the northwest of the Peng-Hu Islands.

For further observation, we collected the time series of satellite-derived (AVHRR and AMSR-E) SST of the waters northwest to the Peng-Hu Islands (square in Fig. 1). Rainfall and wind speed from the weather station in Peng-Hu Islands were also used and compared with the Oceanic Niño Index (ONI, black solid line in Fig. 6). The positive/negative

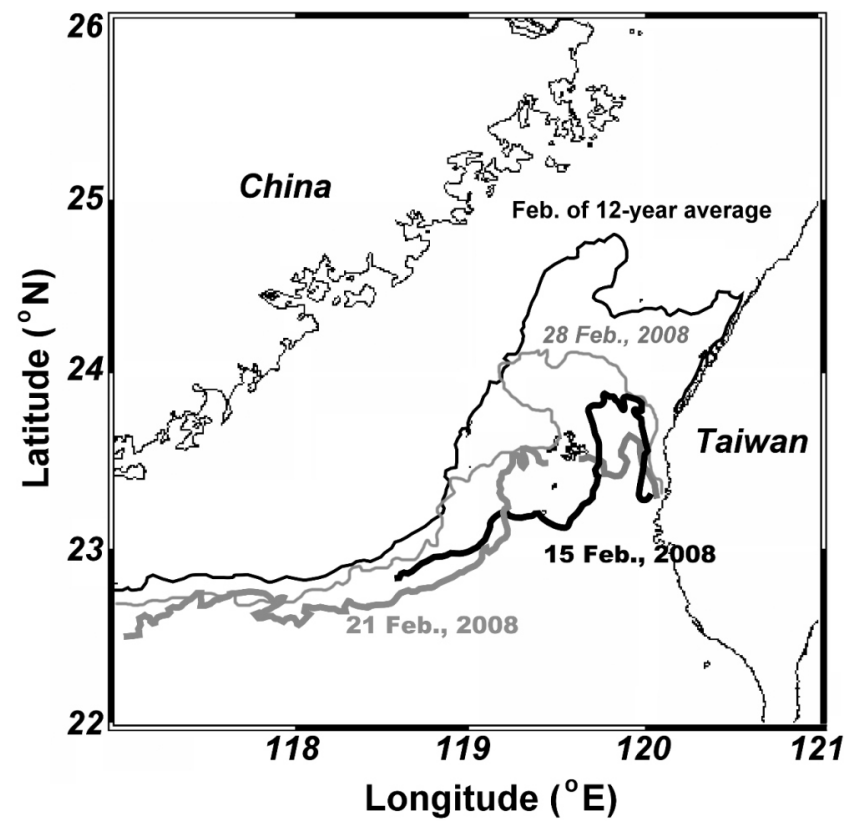

Fig. 5. Contours of $20^{\circ} \mathrm{C}$ of 12 -year average of February (thin black), 15 February (broad black), 21 February (broad grey), and 28 February (thin grey) in 2008 respectively.
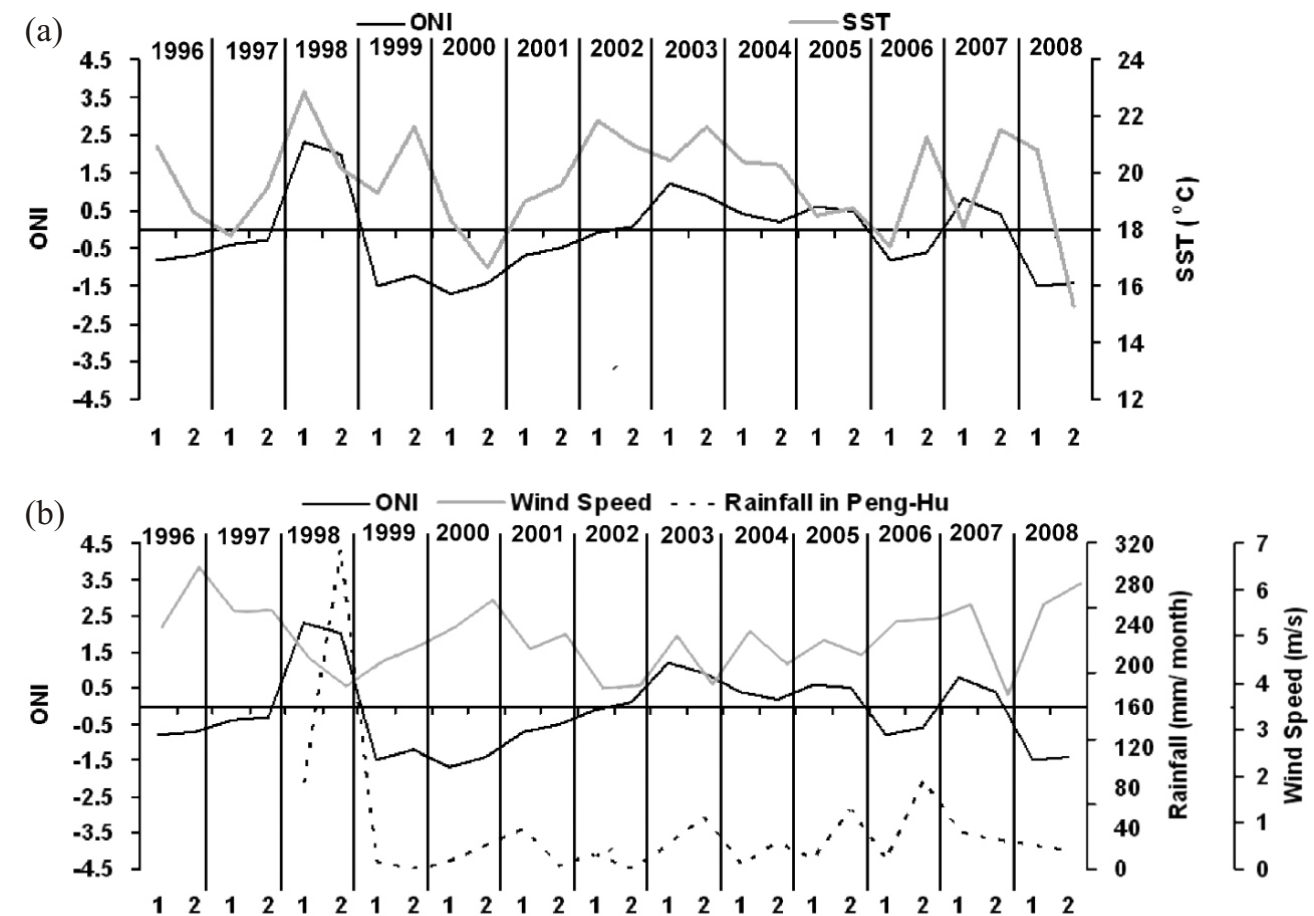

Month

Fig. 6. (a) Time series of Oceanic Niña Index (ONI, black solid line) variation related to SST (grey solid line), (b) Time series of ONI and wind speed (grey solid line) and rainfall (black dotted line). 
values of ONI indicated the La Niña/El Niño events, i.e., cold/warm event in the ocean. Figure 6a shows that SST (grey solid line) varied similarly with the trend of ONI. SST was warmer in the El Niño winters (1998, 2003 - 2005, 2007), but cooler in the La Niña winters (1996, 1999 - 2001, 2008 ). Figure $6 \mathrm{~b}$ also indicates that the wind speed (grey solid line) was more intensive in the La Niña winters (1996, 1999 - 2001, 2006, 2008) than in the El Niño winters (1998, 2003 - 2005, 2007). On the other hand, the rainfall (black dotted line) increased in El Niño winters (1998, 2003 - 2005) but decreased in La Niña winters (1999 - 2001, 2008). Clearly, the wind speed during El Niño/La Niña plays a more important role than the other meteorological factors (e.g., rainfall) in affecting SST variation in the Taiwan Strait. The relationship between wind speed and SST in winter has been further examined and is shown in Fig. 7 indicating that the SST was negatively related to the wind speed with a high correlation coefficient $r$ of -0.62 . In other words, the stronger northeast wind goes with the lower SSTs, and vice versa. We further investigated the inter-seasonal variation of wintertime SST. Figure 8 showed that in general, the SST decreased in January but increased in February (black and grey dots). Compared with satellite-derived SST (AVHRR and AMSR-E), it is noticeable that the speed of the northeast wind (black contour) also varied inter-seasonally but with a trend contrary to that of SST. On the other hand, the variation in both wind speed and SST in 2008 was contrary to those before 2007, that wind speed was lower in January but higher in February. In order to find out if wind change in $\mathrm{La}$ Niña winter causes the large drop of SST $\left(>7^{\circ} \mathrm{C}\right)$ in February of 2008, we thus compared the wind speed and SST in the three relatively intensive La Niña winters $(1999,2000$, and 2008). As shown in Table 1, in 1999 the strong wind (>6 $\mathrm{m} \mathrm{s}^{-1}$ ) lasted for 12 days with a drop of $5.35^{\circ} \mathrm{C}$ in SST (from 19.45 to $14.1^{\circ} \mathrm{C}$ ). The strong wind lasted for 16 days in 2000 and resulted in the decrease of SST from 19.89 to $14.39^{\circ} \mathrm{C}$ $\left(5.5^{\circ} \mathrm{C}\right.$ drop). It is also notable that in 2008 , the strong wind lasted for 30 days and the SST decreased from 20.23 to $12.6^{\circ} \mathrm{C}$ a drop of more than $7.6^{\circ} \mathrm{C}$; however, SST then increased gradually while the wind speed decreased. During this 30 day period, the strong wind had an average of $6.7 \mathrm{~m}$ $\mathrm{s}^{-1}, 2.0 \mathrm{~m} \mathrm{~s}^{-1}$ higher than the 12-year average of February (4.7 $\mathrm{m} \mathrm{s}^{-1}$ ). Furthermore, SST decreased from the end of January and then dropped rapidly in February (arrow in Fig. 8); it is suggested that an exceptional intrusion event happened since early February so that the minimum SST of $12.6^{\circ} \mathrm{C}$ occurred on 16 February, which was $7.8^{\circ} \mathrm{C}$ lower than the 12 -year average of February $\left(20.4^{\circ} \mathrm{C}\right)$. Thus, it is possible that the continuous strong northeast wind may drive more water of the cold China Coastal Current into the Taiwan Strait from the East China Sea. We therefore, have suggested that large cold water mass may in rare instances cross the southern edge of the Chang-Yuen Ridge to reach the Peng-Hu Channel, and the part of this cold current south-

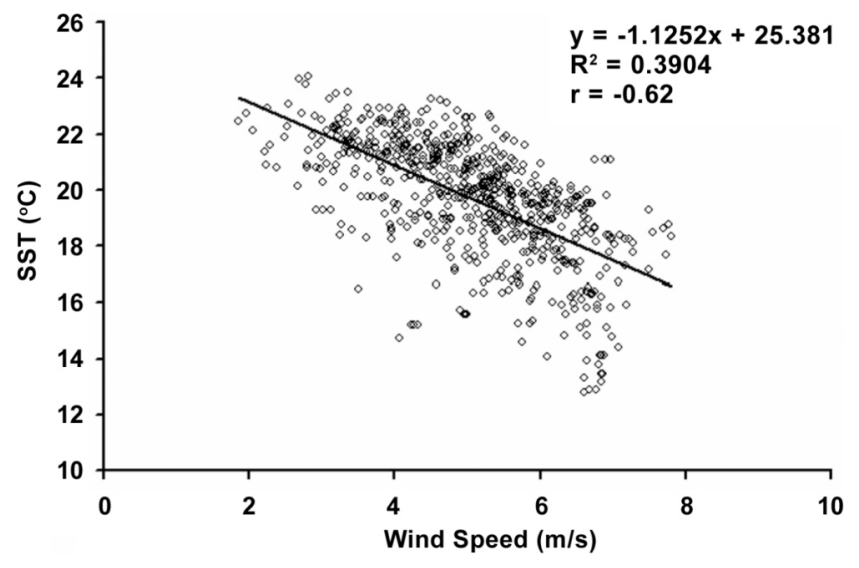

Fig. 7. The relationship between SST and wind speed.

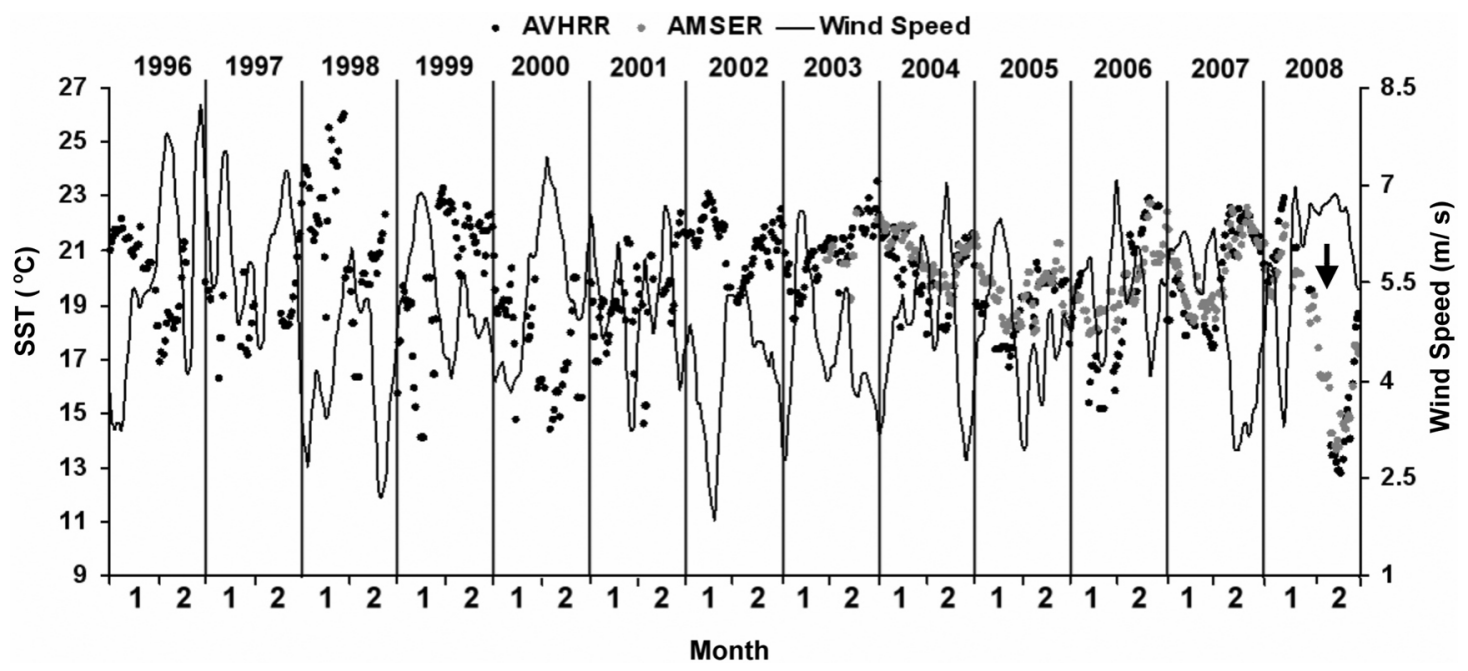

Fig. 8. Time series of the inter-seasonal variation of wind speed (black contour), SST of AVHRR (black dots), and AMSR-E (grey dots). The arrow indicates the beginning of the exceptional intrusion event. 
Table 1. Comparison of daily SST $\left({ }^{\circ} \mathrm{C}\right)$ and wind speed $\left(\mathrm{m} \mathrm{s}^{-1}\right)$ in 3 La Niña winters $(1999,2000$, and 2008).

\begin{tabular}{|c|c|c|c|c|c|c|c|c|c|}
\hline 1999 & $\begin{array}{c}\text { SST } \\
\text { (AVHRR) }\end{array}$ & $\begin{array}{l}\text { Wind } \\
\text { Speed }\end{array}$ & 2000 & $\begin{array}{c}\text { SST } \\
\text { (AVHRR) }\end{array}$ & $\begin{array}{l}\text { Wind } \\
\text { Speed }\end{array}$ & 2008 & $\begin{array}{c}\text { SST } \\
\text { (AVHRR) }\end{array}$ & $\begin{array}{c}\text { SST } \\
\text { (AMSER-E) }\end{array}$ & $\begin{array}{l}\text { Wind } \\
\text { Speed }\end{array}$ \\
\hline $01 / 05$ & 19.45 & 5.52 & $01 / 24$ & 18.24 & 4.88 & $01 / 23$ & 21.06 & 20.23 & 4.99 \\
\hline $01 / 06$ & 19.14 & 5.88 & $01 / 25$ & 18.91 & 4.90 & $01 / 24$ & & 20.11 & 5.46 \\
\hline $01 / 07$ & 18.88 & 6.23 & $01 / 26$ & 19.89 & 6.07 & $01 / 25$ & & 20.11 & 6.21 \\
\hline $01 / 08$ & 19.09 & 6.51 & $01 / 27$ & & 7.56 & $01 / 26$ & & & 7.01 \\
\hline $01 / 09$ & 19.02 & 6.91 & $01 / 28$ & 15.92 & 8.11 & $01 / 27$ & & & 7.36 \\
\hline $01 / 10$ & 17.10 & 7.07 & $01 / 29$ & 16.21 & 7.61 & $01 / 28$ & & & 7.27 \\
\hline $01 / 11$ & 15.95 & 7.06 & $01 / 30$ & 16.12 & 6.91 & $01 / 29$ & & & 6.83 \\
\hline $01 / 12$ & 15.24 & 6.83 & $01 / 31$ & 16.22 & 6.77 & $01 / 30$ & 19.51 & 18.83 & 6.34 \\
\hline $01 / 13$ & & 6.82 & $02 / 01$ & 15.94 & 7.34 & $01 / 31$ & 19.51 & 18.31 & 6.00 \\
\hline $01 / 14$ & & 6.74 & $02 / 02$ & & 7.70 & $02 / 01$ & & 18.91 & 6.16 \\
\hline $01 / 15$ & 14.10 & 6.71 & $02 / 03$ & & 7.50 & $02 / 02$ & & 18.95 & 6.66 \\
\hline $01 / 16$ & 14.10 & 6.69 & $02 / 04$ & & 6.87 & $02 / 03$ & & 19.28 & 7.04 \\
\hline $01 / 17$ & & 6.90 & $02 / 05$ & 14.39 & 6.40 & $02 / 04$ & & 18.46 & 6.98 \\
\hline $01 / 18$ & & 6.61 & $02 / 06$ & 14.77 & 6.28 & $02 / 05$ & & 17.43 & 6.67 \\
\hline $01 / 19$ & 19.98 & 5.97 & $02 / 07$ & 15.13 & 6.30 & $02 / 06$ & & 16.40 & 6.49 \\
\hline $01 / 20$ & 19.98 & 5.40 & $02 / 08$ & 15.79 & 6.52 & $02 / 07$ & & 16.40 & 6.46 \\
\hline $01 / 21$ & 19.98 & 5.49 & $02 / 09$ & 15.81 & 6.60 & $02 / 08$ & & 16.27 & 6.56 \\
\hline $01 / 22$ & 18.43 & 5.68 & $02 / 10$ & 15.79 & 6.42 & $02 / 09$ & & 16.27 & 6.83 \\
\hline $01 / 23$ & 16.46 & 5.31 & $02 / 11$ & 14.84 & 5.79 & $02 / 10$ & & 16.34 & 7.08 \\
\hline $01 / 24$ & 16.46 & 4.56 & $02 / 12$ & 16.01 & 5.22 & $02 / 11$ & & 16.41 & 7.17 \\
\hline \multirow[t]{17}{*}{$01 / 25$} & 18.47 & 4.16 & $02 / 13$ & 16.60 & 4.82 & $02 / 12$ & & 15.91 & 6.93 \\
\hline & & & $02 / 14$ & 16.62 & 4.68 & $02 / 13$ & 13.77 & 14.23 & 6.68 \\
\hline & & & $02 / 15$ & 16.88 & 4.86 & $02 / 14$ & 13.46 & 14.23 & 6.63 \\
\hline & & & $02 / 16$ & 19.97 & 5.08 & $02 / 15$ & 13.46 & 13.81 & 6.72 \\
\hline & & & $02 / 17$ & 19.97 & 4.04 & $02 / 16$ & 13.16 & 13.66 & 6.74 \\
\hline & & & $02 / 18$ & 18.80 & 5.80 & $02 / 17$ & 12.90 & 14.02 & 6.54 \\
\hline & & & $02 / 19$ & 19.97 & 5.08 & $02 / 18$ & 12.87 & 13.74 & 6.46 \\
\hline & & & $02 / 20$ & 19.97 & 4.04 & $02 / 19$ & 12.79 & 14.96 & 6.44 \\
\hline & & & & & & $02 / 20$ & 13.30 & 14.63 & 6.68 \\
\hline & & & & & & $02 / 21$ & 13.92 & 14.43 & 6.86 \\
\hline & & & & & & $02 / 22$ & 14.81 & 14.39 & 6.82 \\
\hline & & & & & & $02 / 23$ & 15.13 & 14.78 & 6.12 \\
\hline & & & & & & $02 / 24$ & 15.60 & 14.91 & 5.11 \\
\hline & & & & & & $02 / 25$ & 14.06 & 14.82 & 4.60 \\
\hline & & & & & & $02 / 26$ & 16.07 & 15.98 & 4.80 \\
\hline & & & & & & $02 / 27$ & 16.91 & 17.54 & 5.41 \\
\hline & & & & & & $02 / 28$ & 18.16 & 17.51 & 5.80 \\
\hline
\end{tabular}


west to the Ridge also intruded into the south of the Peng-Hu Islands. Consequently, the exceptional cold SSTs around the Chang-Yuen Ridge and Peng-Hu Islands in February of 2008 probably were caused by the more southward intrusion of the China Coastal Current driven by the continuous strong wind.

Kuo and Ho (2004) indicated that the northeasterly wind in the La Niña winter of 1998/1999 was much stronger than the El Niño winter of $1997 / 1998$. This climate change in wind stress resulted in lower SST in the Taiwan Strait in the La Niña winter. Referring to the ONI, SST, and wind speed (Fig. 6), this decadal oscillation was consistent with that discussed by Kuo and Ho (2004). The strong wind induced by climate change clearly seen in the La Niña winters, especially, the continuous strong wind in the La Niña winter of 2008, may drive the China Coastal Current more southward to the Peng-Hu Islands and result in the drop of $7.8^{\circ} \mathrm{C}$ in SST, a drop far lower than the 12-year average. Obviously, such rapid change in the marine environment also affects the marine ecology; more than 130 tons of coral reef and caged aquaculture fishes perished around the coastal waters of the Peng-Hu Islands during this cold SST period (unpublished data). The turbulent mixing condition of the upper ocean was generally estimated by a wind-mixing index, which is proportional to the cube of the wind velocity (Bakun and Parrish 1991). Thus this phenomenon may be similar to that suggested by Wroblewski and Richman (1987) who indicated that wind mixing may have negative effects by creating a turbulent environment that reduces feeding efficiency of marine life or drive them away from suitable habitats. The cold SST event or intrusion of the China Coastal Current in the present study was rare for these waters; however, it is difficult to identify the relationship between the intrusion and wind speed, even if the wind speed was quite strong and lasted for a long period (i.e., 30 days) as it did in February of 2008. Analyses of in situ data combined with modeling simulation should be undertaken to improve our understanding of such exceptional SST variation in the Taiwan Strait. The influence of different strengths of climate change in wind fields should be considered in further studies.

\section{SUMMARY}

By using AVHRR high-resolution $(1.1 \mathrm{~km}) \mathrm{SST}$ data form 1996 - 2008, we were able to identify the exceptional intrusion of the China Coastal Current in the Taiwan Strait in the La Niña winter of 2008. The spatial distribution of cold and warm water is always bounded in the central Taiwan Strait. There is a clear SST front occurring between the cold water in the northwestern and the warm water in the southeastern Taiwan Strait. This front belt in the Taiwan Strait shifts mainly inter-seasonally; it always appears more southerly in January and moves to the north of the Chang-Yuen Ridge in February.

Meanwhile, the wind speed in the Taiwan Strait also varies inter-seasonally but with the reverse direction of SST. The strong wind speed usually occurs in January with the lower SST and wind speed decreases gradually in February while the SST becoming higher. However, the unusual wind variation was observed in the La Niña winter of 2008, the wind speed was relative low in January but significantly increased to last for about 30 days into February. This exceptional change in wind speed exerted a direct influence on the current distribution and the SST fields within the Taiwan Strait. It is suggested that the continuous strong northeast wind drove the China Coastal Current southward to penetrate into the Peng-Hu Channel from north of the ChangYuen Ridge and a portion of this current intruded south of the Peng-Hu Islands from its west side, SST in this area was therefore much lower than usual.

Acknowledgements This study was supported by a research grant (97529002B2) awarded by the Center for Marine Bioscience and Biotechnology, NTOU, and another two grants (95-2119-M-019-002 and 96-2611-M-019007) provided by the National Science Council, Taiwan. The authors would like to thank Ms. Jui-Wen Chan and Ms. WeiJuan Shieh, both of the Remote Sensing Laboratory of Taiwan Ocean Research Institute, for their support on the satellite data processing. The authors would also express their appreciation to Professor Chang-Tai Shih of NTOU for his helpful advice on this manuscript.

\section{REFERENCES}

Bakun, A. and R. H. Parrish, 1991: Comparative studies of coastal pelagic fish reproductive habitats: The anchovy (Engraulis anchoita) of the southwestern Atlantic. ICESJ. Mar. Sci., 48, 343-361, doi: 10.1093/icesjms/48.3.343. [Link]

Chang, Y., T. Shimada, M. A. Lee, H. J. Lu, F. Sakaida, and H. Kawamura, 2006: Wintertime sea surface temperature fronts in the Taiwan Strait. Geophys. Res. Lett., 33, L23603, doi: 10.1029/2006GL027415. [Link]

Hosoda, K. and H. Kawamura, 2004: Global space-time statistics of sea surface temperature estimated from AMSR-E data. Geophys. Res. Lett., 31, L17202, doi: 10.1029/2004 GL020317. [Link]

Jan, S. and S. Y. Chao, 2003: Seasonal variation of volume transport in the major inflow region of the Taiwan Strait: The Penghu Channel. Deep-Sea Res. II, 50, 1117-1126, doi: 10.1016/S0967-0645(03)00013-4. [Link]

Jan, S., J. Wang, C. S. Chen, and S. Y. Chao, 2002: Seasonal variation of the circulation in the Taiwan Strait. J. Mar. Syst., 35, 249-268, doi: 10.1016/S0924-7963(02)00130-6. [Link]

Jan, S., D. D. Sheu, and H. M. Kuo, 2006: Water mass and throughflow transport variability in the Taiwan Strait. $J$. Geophys. Res., 111, C12012, doi: 10.1029/2006JC003656. [Link] 
Kuo, N. J. and C. R. Ho, 2004: ENSO effect on the sea surface wind and sea surface temperature in the Taiwan Strait. Geophys. Res. Lett., 31, L13309, doi: 10.1029/2004GL 020303. [Link]

Lee, M. A., C. D. Yeah, C. H. Cheng, J. W. Chan, and K. T. Lee, 2003: Empirical orthogonal function analysis of AVHRR sea surface temperature patterns in Taiwan Strait. J. Mar. Sci. Technol., 11, 1-7. [Link]

Lee, M. A., Y. Chang, K. T, Lee, D. C. Liu, and W. C. Su, 2005a: A satellite and field view of the winter sea surface temperature variability in Taiwan Strait. In Proceedings of IEEE IGARSS 2005, Seoul, Korea, Vol. II, 2167-2173.

Lee, M. A., Y. Chang, F. Sakaida, H. Kawamura, C. H. Cheng, J. W. Chan, and I. Huang, 2005b: Validation of satellite- derived sea surface temperatures for waters around Taiwan. Terr. Atmos. Ocean. Sci., 16, 1189-1204.

McClain, E. P., W. G. Pichel, and C. C. Walton, 1985: Comparative performance of AVHRR-based multichannel sea surface temperatures. J. Geophys. Res., 90, 11587-11601, doi: 10.1029/JC090iC06p11587. [Link]

Wroblewski, J. S. and J. G. Richman, 1987: The non-linear response of plankton to wind mixing events - Implications for survival of larval northern anchovy. J. Plankton Res., 9, 103-123, doi: 10.1093/plankt/9.1.103. [Link]

Xue, Y., T. M. Smith, and R. W. Reynolds, 2003: Interdecadal changes of 30-yr SST normals during 1871-2000. J. Climate, 16, 1601-1612. [Link] 